\title{
PODER CONSTITUYENTE, PRINCIPIO DEMOCRÁTICO Y CONTINUIDAD EN EL TRATADO CONSTITUCIONAL DE LA UNIÓN EUROPEA
}

\author{
GONZALO MAESTRO BUELGA \\ Catedrático de Derecho Constitucional \\ Universidad del Pais Vasco
}
ÍNDICE
I. Introducción.
II. El deficit democrático.
III. La constitución compuesta o multinivel y el principio democrático
IV. Proceso constituyente y poder constituyente en la convención europea
V. La continuidad del proyento de la convención europea
VI. Conclusiones.

\section{INTRODUCCIÓN.}

La reapertura del debate constitucional europeo, después de nuestras últimas elecciones repropone muchas de las cuestiones presentes en un proceso constituyente atípico, en el que faltan los requisitos de democraticidad que permitan calificarlo de esta manera. Sin embargo, el proceso iniciado por la Convención intenta apropiarse de ese carácter, en el sentido que pretende inagurar un nuevo orden en una nueva situación, entendiendo por tal la derivada de la ampliación.

La paradoja expuesta obliga a realizar algunas consideraciones en torno al proceso que ha culminado la Convención, en la tentativa de dar alguna explicación, tanto al procedimiento formal, como a los contenidos que el texto aprobado a mediados del año 2003 incorpora. Ciertamente, esta reflexión no puede prescindir de consideraciones que afectan a la misma raíz de la integración europea y a la relación que se establece entre los espacios nacionales y el europeo. Estas cuestiones son la base de partida para análisis de la solución finalmente adoptada. 
les de un ordenamiento que se construye desde la prevalencia del mercado, piedra basilar del mismo, incluso en su nueva versión. A la vez, esta infiltración se produce sin la configuración de espacios políticos sujetos al control democrático, sin resolver el problema del deficit democrático que justificaba o, incluso exigia, una Constitución europea. Desde esta perspectiva, el texto de la Convención resulta más problemático, aumenta la tensión entre los ordenamientos estatales y el europeo y debilita aún más la normatividad de la constitución de los Estados, que, no se olvide, formalmente aparecian vinculadas al constitucionalismo social. Las construciones doctrinales que articulaban la relación entre los niveles estatal y europeo en torno a la fórmula de la «constitución multinivel» acaban por brindar un marco interpretativo útil en la medida en que reconstruyen un complejo ordinamental en el que la instancia europea actua como reestructuradora de la constitución global imponiendo un nuevo modelo, que actua exento de las condiciones de legitimidad que imponía la teoría constitucinal democrática surgida de la segunda postguerra mundial.

\section{EL DEFICIT DEMOCRÁTICO.}

\subsection{Los Estados y LA COMUNIDAD EN LA LEGITIMACIÓN DEMOCRÁTICA.}

Como hemos señalado el debate sobre el deficit democrático en la CEE se reaviva con la ampliación de competencias de esta y con la paulatina limitación del criterio de la unanimidad como mecanismo decisional. En un primer momento la intergubernamentalidad prevalente y la limitadas competencias hacian recaer la legitamación de las decisiones comunitarias en la democraticidad de los Estados miembros, que operaban como prestadores de legitimimidad y permitian la sustracción del espacio decisional cedido a los controles impuestos por el principio democrático. La especificidad de la CEE imponía este modelo, esta era concevida no como una organización internacional sino que en su ámbito competencial actuaba sin sometimiento a los Estados, aunque la intergubernamentalidad predominante atenuase la autonomía de la CEE. Es sobre esta base como se fundamentó la supremacía del Derecho comunitario.

La fórmula que el Proyecto de Tratado Constitucional incorpora para abordar el problema del deficit democrático no innova respecto a la situación anterior, si bien atenua los efectos de su visualización con el incremento de poderes del Parlamento. La legitimación de la Comunidad se fundaba en un doble sistema en los Pueblos y en los Estados ${ }^{4}$. La estatal es una legitamación indirecta, que deriva del carácter democrático de los Estados miembros que, actuando a través de sus gobiernos, transfieren la democraticidad a la Comunidad. La segunda es directa y, desde que el Parlamento se conforma medinte la elección directa, vincula a los pueblos con el proceso decisional europeo. Debe notarse que la vinculación en la precaria legitimación directa es con los pueblos de los Estados miembros ${ }^{5}$, pues la base electoral es nacional y el proceso contagiado por el contexto de cada Estado ${ }^{6}$.

1 WEILER, J.H.H. The constitution of Europe. Cambridge U.P., 1999, PP. 10-5

2 GRIMM, D. «iNecesita Europa una constitución?» en Debats, 1996, n 55,pp 4 y ss. HABERMAS, J. « Observaciones a» ¿Necesita Europa una constitución? « en Debats, 1996, n 55, pp. 21y ss. 
El debate sobre la constitución europea tiene al menos dos dimensiones, una jurídicoformal que se deriva de la caracterización que el TJCE ha realizado del Ordenamiento comunitario y, otra, vinculada a la cuestión del deficit democrático de la Comunidad, que se ha intensificado desde la aceleración del proceso de integración que supuso el Acta única. La primera dimensión, además de las cuestiones técnicas derivadas de la construcción jurisprudencial, plantea el problema de la relación entre ordenamientos desde una prespectiva funcional. La prevalencia del Ordenamiento comunitario respecto al de los Estados miembros no es solo una cuestión vinculada a la necesaria afirmación del Derecho comunitario como fórmula y garantía de subsistencia de la Comunidad ${ }^{1}$, sino que cobra su sentido en el contexto de la contraposición entre las constituciones materiales de la CEE y la de los Estados, vinculadas al constitucionalismo social. La segunda cuestión afecta a la legitimación del Ordenamiento comunitario. Ciertamente, el deficit democrático se ha planteado paralelamente a la ampliación de competencias de la Comunidad y a los cambios en los procesos de decisión, ambos elementos han significado la sustracción al ámbito político estatal de espacios relevantes de la política, sin que se haya operado su traslación a un espacio político europeo aún inexistente. Las dos cuestiones están, en nuestra opinión intimamente relacionadas.

La minoración del espacio político nacional, de aquel que se correspondía con la nueva definición del mismo que se había producido con la instauración del Estado social, es funcional a las dificultades de legitimación producidas por la ruptura de esta forma de Estado, operada en gran medida a través del Ordenamiento europeo. Las pretensiones de teorizar la Constitución europea en torno a la idea de un nuevo constitucionalismo que integre los dos espaciós politicos no resuelve el problema de la legitimidad de la Comunidad, al contrario desvela, en su construcción, la reducción del ámbito político, colocado ahora en el limbo de lo indecidible por su traslación a un espacio no regido por el principio democrático.

El debate en torno a la constitucionalización de la Unión europea, como fórmula para su democratización ${ }^{2}$, aparece como no superado, las aportaciones de la Convención, que se recogen en el texto, no resuelven los problemas planteados, a pesar del reforzamiento de los poderes del Parlamento. No solo el contenido del Proyecto no supone una solución a la minoración del espacio político que las últimas reformas de los Tratados sancionaban, sino que su forma de elaboración resulta consustancial a esa minoración. La apropiación del poder constituyente operada por la Convención, con la pretensión de una apertura participativa en contraste con las experiencias previas de reforma de los Tratados, evidencia aún más el deficit democratico y lo vincula funcionalmente al proyecto europeo que refleja su contenido.

El contenido constitucional presenta en una primera aproximación una aparente paradoja, por una parte avanza en la configuración de un ordenamiento de caracter universalista, colmando un deficit constitucional evidente respecto a los Tratados ( Carta de derechos, unificación de la Comunidad y la Unión ... ), por otra su contenido fuerte sigue siendo de caracter económico y en este la continuidad, respecto a los Tratados, es evidente ${ }^{3}$ La universalización del Ordenamiento europeo agudiza los problemas de relación interordinamental en la medida en que refuerza la capacidad de penetración en los ordenamientos naciona-

3 DI PLINIO, G. «La costituzione economica nel processo costituente europeo» en Diritto Pubblico Comparato ed Europeo, 2003-IV, pp 1780 y ss. 
forma, la política europea. Por otra parte esta fórmula solo tiene efectos retóricos, tendentes a reforzar el sistema de doble legitimación expresado en el Proyecto de la Convención. No puede pretenderse que la via indirecta, de los Estados miembros, complete la legitimación democrática de la Unión cuando estos actuan sobre un espacio virtual, sustraido a su actuación. La intervención, atenuada, en defensa del principio de subsidiariedad, no resuelve nada, y no lo hace porque la legitimación indirecta solo pretende encubrir la debilidad de los canales de participación directa y del espacio politico europeo. La propuestas que se han realizado, a la luz del texto de la Convención, por esta razón, han incidido en convertir al Parlamento europeo en un órgano lo más parecido al los parlamentos estatales, aún siendo conscientes de que incluso esta fómula tiene, en el contexto europeo, sus limitaciones.

Situado el problema del deficit democrático y su tratamiento en el Tratado Constitucinal, conviene realizar algunas alusiones a las posiciones que pretenden eludir la cuestión de la democraticidad desplazandola a otros campos. La fuente de legitimidad deja de ser ahora la democrática para trasladarse a la técnica o al derecho, reconociendo implicitamente la dificultad de resolver una cuestión que tiene dificil encaje en esta fase del proyecto europeo.

Nos interesa detenernos en dos de las propuestas de legitimación del Ordenamiento europeo que minimizan el alcance de la dimensión democrática en este ámbito. Una de ellas, significativa porque situa la legitimación en la dimensión técnica, la misma que justifica los órganos reguladores, configurando al espacio europeo como sustraido a la lógica democrática. La otra es la que hace recaer en el derecho la legitimación, en este caso dos son las versiones, aquella que en torno al principio de legalidad y al «Estado de derecho» justifican un proceso decisional sustraido a la participación ciudadana, esa otra que ve en los Derechos fundamentales no solo su fuente de legitimación sino tambien el fundamento de la constitucionalidad del ordenamiento europeo.

La primera de ellas tiene a su portavoz más autorizado en Majone ${ }^{10}$. La base de partida es la imposibilidad de fundar la legitimación de la Unión en el principio democrático por la ausencia de un pueblo europeo. La tesis de la inexistencia del demos europeo justifica la busqueda de otra fuente que se encuentra en teorias económicas trasladadas a la politica, vinculadas a la eficacia, y en la literatura sobre las institucines reguladoras (las autoridades independientes ). Pero más que esta fundamentación nos interesa destacar la caracterización que realiza del la CEE. El principio organizador de la Comuniad no es, dice, la separación de poderes, sino la representación de intereses, cada institución de la CEE pretende representar un interés y se organiza funcionalmente para ese cometido. Lo que determina el proceso decisional es, por tanto, la naturaleza del interés a representar, lo que en principio es ajeno a la lógica democrática. Los intereses en juego son tanto los nacionales, de los paises miem-

4 PETRANGELI, F. «Processo di riforma dell’Unione e questione democratica» en Democrazia e Diritto, $2003, \mathrm{n}^{\circ} 2$, pp114 yss.

5 DELLAVALLE, S. «La legittimazione del potere pubblico europeo» en Teoria Politica, 2003, n 1 , pp 43 y ss.

6 REIF, K. “ European election as Member State Second-Order election revisited “ en European Journal PoliticalResearch, 1997, no 32, pp115 y ss.

7 HABERMAS, J. «Observaciones a «¿Necesita Europa una constitución?», op. cit.

8 Para la literatura politológica sobre el sistema de partidos europeo ver BARDI, L. «I partiti e il sistema partitico dell?Unione europea» en L'Unione europea, Bari, Laterza, 2002. 
El texto de la Convención no innova en esta fórmula, la apelación a los pueblos de Europa del preámbulo no se vé contradicha por la declaración del artículo 1, que dista mucho de las fórmula que el constitucionalismo estatal utiliza para la legitimación del poder político. La referencia a los «ciudadanos y los Estados miembros» reproduce en el Proyecto lo que era una construcción difusa y aceptada doctrinalmente. Ciudadanos, en este caso, no viene a significar la propuesta de pueblo que Habermas realiza en su debate, de sobra conocido, con Grimm, sino que se relaciona con el esquema lagitimador ya señalado. El problema de la legitimación directa no afecta solo a las competencias del Parlamento europeo, único organo representativo en la estructura de poderes de la Unión, sino, como ha sido señalado por la doctrina ${ }^{7}$, a la creación de un espacio político europeo, que no existe ${ }^{8}$. A falta de la creación de este espacio la legitación directa queda afectada. En el debate europeo, las opciones en juego, en definitiva, los términos de la competencia política no son aquellos propios de este ámbito, sino de la política estatal, continuando la política europea fuera del espacio decisional vinculado al principio democrático. Todo ello sin referirnos al papel del Parlamento que, a pesar del incremento de sus funciones dista mucho de ser el equivalente de la institución nacional. La desviación de la organización institucional europea del modelo de separación de poderes, las peculiaridades del proceso legislativo, los ámbitos sustraidos al Parlamento en el proceso legislativo y la centralidad institucional del Consejo, que no puede, por mucho que se pretenda, incluirse en la lógica de las segundas cámaras en representación de los Estados, parlamentarizando esta institución, debilitan las posibilidades legitimadoras del Parlamento. Así el Proyecto de la Convención no resuelve los problemas del deficit democrático planteados hasta ahora, sino que sanciona el sistema de legimitación que había funcionado hasta el momento. El artículo I-46 del Proyecto, central dentro de las disposiciones sobre la vida democrática, sanciona la doble via «Los ciudadanos estarán directamente representados en la Unión a través del Parlamento Europeo. Los Estados miembros estarán representados en el Consejo Europeo y en Consejo de ministros por sus gobiernos, que seran responsables ante los parlamentos nacionales elegidos por sus ciudadanos».

La apelación como criterio de legitimación democrática a los Estados miembros, que contribuyen a definir el sistema de democracia representativa de la Unión, viene completado con las referencias al papel de los parlamentos nacionales en el sistema decisional europeo. Los parlamentos nacionales entran en el circuito representativo, contribuyendo a paliar el deficit democrático, mediante el «Protocolo sobre el cometido de los parlamentos nacionales en la Unión Europea», adjunto al tratado como anexo del mismo, y que se consideraran parte del mismo (art. IV-442). Las funciones de estos se relacionan con la aplicación de principio de subsidiariedad e incorpora un sistema de información previa en los procedimientos legislativos. La intervención parlamentaria se concluye con la posibilidad de la emisión de un dictamen respecto al respeto del principio de subsidiariedad. La Convención, por razones de racionalidad decisional, amen de por las dificultades de introducir a la instancia nacional en el sistema institucional de la Unión, rechazó la creación de una cámara de los pueblos en los términos en que había propuesto su presidente ${ }^{9}$. Las soluciones que por este lado se han articulado no contribuyen a paliar el deficit democrático, en la medida en que el espacio político nacional no recobra, como no podía ser de otra

9 DELLAVALLE, S. «La legittimazione del potere pubblico europeo», op. cit. 
paradoja europea, aquella del maximalismo jurídico y el minimalismo político ${ }^{12}$. El derecho exime de la construcción del espacio europeo que ya no opera como legitimación del poder, este es suficiente para justificar la decisión. El esquema recuerda al Estado de Derecho liberal y a la tensión democrática en su seno.

La definición de la Comunidad como «comunidad de derecho» que construyó la jurisprudencia europea, no solo permitió configurar a los Tratados como constitución, sino que operaba como mecanismo legitimador estableciendo una exigencia de legalidad reforzada a la actuación comunitaria. La apelación al Estado de derecho en el interior del Ordenamiento comunitario, con el contenido que se adjudica a esta fórmula, especialmente la legalidad y una lectura del equilibrio de poderes ${ }^{13}$, acaba justificando el proceso decisional no directamente vinculado al principio democrático y permitiendo el funcionamiento de una legitimación indirecta.

Si esta primera fórmula aparece débil, la legitimación por el derecho a sido reforzada por el papel que se ha adjudicado a los Derechos en el Ordenamiento comunitario ${ }^{14}$, acentuado por la visible aparición normativa de estos desde Niza. Los derechos y su reconocimiento normativo, dada la especial peculiaridad del sistema jurisprudencial construido por el TJCE, aparecían como un obstáculo fundamental para caracterizar al Odenamiento comunitario como constitucional, con el efecto legitimador que esto colleva. La aprobación de la Carta de Derechos fundamentales de la Unión Europea, parece colmar este deficit ${ }^{15}$, sobre todo despues de su incorporación al texto del Proyecto de la Convención ${ }^{16}$. Los derechos operan, ahora sin las reservas anteriores, como forma de convalidación de las carencias democráticas que vuelven a recaer en fórmulas indirectas.

La recepción en el Derecho originario comunitario de la dimensión legitamante de los Derechos se ha materializado en los artículos 6 y 7 de la versión consolidada del Tratado de la Unión europea. No solo la Unión se basaría en los Derechos, reconociendo un nuevo fundamento que le alejarian de la unidimensional lógica del mercado ${ }^{17}$, sino que esta introduciría como criterio de permanencia la observancia de los mismos a través de mecanismos disciplinantes.

Los preceptos de referencia, en algunas construcciones doctrinales, han fundamentado la contrucción de la «homogeneidad constitucional» del orden europeo capaz de legitimar el proceso de constitucionalización que ahora integra, ya normativamente, unas bases comunes ${ }^{18}$.El Ordenamiento comunitario se justifica en cuanto permite un estandar suficiente de tutela de los derechos, visualizado por su reconocimiento normativo al máximo nivel. Es como si se recobrase una legitimación iusnaturalista que sin embargo no incorpora los elementos del contractualismo. Los derechos como forma de suplencia democrática que permite una incorporación débil de la misma, idea que esta presente en la misma Carta. La concepción de la democracia que el título VI «De la vida democrática de la Unión», del Tratado Constitucional y del tílulo V de la Carta, contrasta con el peso de los derechos del ámbito privado ${ }^{19}$. Parece como si en El Tratado hubiera vencido Constant frente a la tradición del constitucionalismo de la II postguerra mundial.

10 MAJONE, G. «Europe's«democratic deficit»: the question of standars« en European Law Journal, 1998, $\mathrm{n}^{\circ} 1$, pp 5 y ss. Tambien« Nonmajoritariam institutions and limits of democratic governance: A political transaction-cost aproach« en Journal of Institutional and Theoretical Economics, 2001, pp 57 y ss. Más recientemente « Deficir democratico, istituzioni non-maggioritarie ed il paradosso dellìntegrazione europea« en Stato e Mercato, 2003, $\mathrm{n}^{\circ}$ 67, pp 3 y ss. 
bros, como un interés general de la Comunidad, o incluso intereses de tipo corporativo o privado. Esta «comunidad de intereses» obliga a que los procedimientos se articulen mediante formas de composición de los mismos, y otorgando la capacidad decisional a aquel que tenga encomendada la defensa de un interés especifico. El espacio para una legitación democrática se contrae radicalmente cuando la representación general no es el objeto del proceso decisional, sino la composición de intereses.

El papel de la Comisión, órgano con una precaria legitimación democrática, se justifica por su función de defensa de un interés comunitario no reconducible a intereses generales, al contrario, vinculado a la construcción del mercado único y a la tutela de su funcionamiento. Esta forma la legitimación de las instituciones «no mayoritarias», que se sustraen a procedimientos y responsabilidad política, es por naturaleza refractaria al principio democrático, su eficacia descansa en otro fundamento. El papel «super partes» de la Comisión, en la defensa del interés de la Comunidad justifica la desconesión con vinculos politicos y su sistema de responsabilidad. La eficacia en el proceso decisional exige mantener espacios exentos de la lógica democrática, así lo ha demostrado la historia del proceso de integración y así parece recomendarlo el futuro. «Parece claro que integración económica e integración política deben seguir caminos separados, con todas las consecuencias prácticas y normativas que se derivan de la separación de la economía y de la política. El papel limitado que los tratados europeos asignan a la democracia se refleja... en la misma arquitectura institucional de la comunidad $»^{11}$. En un ordenamineto prevalentemente económico, que debe permanecer sujeto a sus propias reglas, la legitimación democrática juega un papel menos decisivo y puede permanecer en una posición secundaria, esta es en definitiva la propuesta que se nos hace y que puede extrapolarse al actual proceso constituyente. Anunque la legitimación de la comisión en el sistema institucional ha cambiado en el tratado constitucional respecto a la situación anterior, es significativa esta tesis en cuanto desvaloriza la importancia del principio democrático

\subsection{LA LEgitimación POR El DERECHO.}

Las propuestas de legitimación por el derecho minusvaloran la necesidad de una fundación democrática del poder europeo. La apelación al derecho, en sus diversas formulaciones, pretender compensar el deficit democrático mediante la apelación al vínculo normativo. El derecho ahora juega, no solo un papel sustitutorio del principio democrático, sino que tambien sierve para justificar la ausencia de un espacio político europeo, el deficit político, la sustración del espacio preferencial de la política en el Estado social ( el de la economía), que se traslada a un ámbito de no rseponsabilidad. Esa es una de las consecuencias de la

11 MAJONE, G. «Deficit democratico, istituzioni non-maggioritarie ed il paradosso dellintegrazione europea», op.cit

12 CANTARO, A. Europa sovrana. La costitución dell'Unione tra guerra e diritti, Ed Dedalo, Bari, 2003.

13 CASSESE, S.«Is really a "democratic deficit" en Institutional refroms in the European Union, Roma, Europeos, 2002, pp 24 y ss. Tambien» Law as instrument fo integration. New balance of powers and legitimacy en European Union. 1998.

14 AZZENA, L. L'integrazione attraverso i diritti. Del cittadino italiano al cittadino europeo. Giappichelli. Turin, 
en los momentos fundacionales y en su desarrollo. El pueblo se crea jurídicamente, su diversidad esencial no es obstáculo. La expresión democrática, aunque en su materialización europea sea precaria, consolida el «demos europeo» que legitima este orden compuesto.

Ciertamente, el momento democrático que debe prestar la legitimación en esta construcción se articula de forma paradójica, el ámbito global que adolece de una debilidad estructural en este sentido, se contagia del estatal que presta la legitimidad que colma el déficit».

La construcción de la constitución compuesta precisa de la desestatalización del propio concepto, en este sentido la propuesta teórica es la inversa a la que se realiza para comprometer el carácter constitucional del Ordenamiento europeo. La primera idea es la de Constitución sin Estado ${ }^{25}$. La separación de ambos conceptos permite articular un nuevo espacio normativo global en el que se integran los ordenes estatales.

La ruptura entre Estado y Constitución se realiza, tanto a través de la acentuación del contractualismo como fuente legitimante del constitucionalismo ${ }^{26}$, como a través del pluralismo, como carácter intrínseco del ordenamiento europeo ${ }^{27}$.

Lo trascendental es el acuerdo fundante, en el primer caso, la voluntad colectiva asume el papel determinante en la legitimación del ordenamiento compuesto, sin que resulte trascendente la relación teórica e histórica entre Constitución y Estado. En el segundo caso, complementariamente, la afirmación del pluralismo comunitario obliga a atenuar el vínculo estatal, por otra parte, ya debilitado en las relaciones con la Europa supranacional.

La constitución compuesta de la Unión europea es definida en torno a tres parámetros: que el ordenamiento europeo, la Constitución, es un sistema único, que este está compuesto por dos niveles, el nacional y el de la Unión y, por último, que en este sistema, las relaciones no están ordenadas jerárquicamente. «La constitución europea es un único sistema, compuesto por dos niveles constitucionales complementarios: el Europeo y el nacional, los cuales están íntimamente entretejidos y son interdependientes. Uno no puede ser leído y plenamente entendido sin mirar al otro» ${ }^{28}$. La propuesta pretende superar la contradicción estatalismo-.supraestatalismo en la dinámica europea ${ }^{29}$, pero lo hace dando una centralidad a la visión supranacional que estructura la propuesta. La unicidad del sistema no surge sólo de la interconexión de los ordenamientos estatales y de la Unión, sino de la prevalencia del orden global que se teoriza.

La tesis fundamental de constitucionalismo multinivel es pues el de la unicidad. Ordenamiento compuesto, complejo, pero único. Ciertamente, esta cualidad del ordenamiento europeo se articula sobre dos bases: la construcción jurisprudencial del TJCE conceptualizada en torno al término «comunidad de derecho», la supremacía y el efecto directo de sus normas, unidas al elemento fáctico, representado por la afectación de los

15 FIORAVANTI, M. «La Carta dei Diritti Fondamentali dell’Unione Europea nella prosprttiva del costituzionalismo moderno» en Istituzioni mercato e democrazia, Giappichelli, Turin 2002, pp 255 y ss.

16 Literatura sobre la Carta de Niza

17 CUOCOLO, F. «L'Europa del mercato e l'Europa dei Diritti» en Quaderni Costituzionali, 2000, pp 587 y

SS

18 MICCU, R. «Principio di omogeneitá nel processo di costituzionalizzazione dell’Unione europea», en curso de publicación.

19 FERRARA, G. «Da Weimar a Maastricht» en La Rivista del Manifesto, octobre 2000, pp24 y ss. 


\section{LA CONSTITUCIÓN COMPUESTA O MULTINIVEL Y EL PRINCIPIO DEMOCRÁTICO.}

Para el analisis que estamos haciendo conviene detenernos en las teorizaciones en torno a la idea de la constitución compuesta o constitucionalismo multinivel, en la medida en que estas propuestas permiten una articulación de espacios políticos: Estados y Comunidad, que afectan al principio democrático.

Desde la dimensión normativa, ya en los años noventa, han aparecido una serie de propuestas de caracterización del ordenamiento europeo que coinciden en señalar su carácter complejo, integrado por varios niveles, tanto el comunitario, como el estatal. Dando lugar a una conceptualización que hemos representado en la fórmula de «constitución compuesta», propuesta por Cassese $^{20}$, pero en la que coinciden un abanico significativo de autores.

La aceleración del ritmo de integración europea desencadenada por el Acta Unica pero impulsado definitivamente en Mastricht alienta una nueva teorización sobre el ordenamiento europeo y su relación con los ordenamientos de los Estados miembros ${ }^{21}$. El proceso de integración acaba por sancionar como evidente la erosión de la autonomía estatal ${ }^{22}$ obligando a formalizar teóricamente una nueva interrelación. Sin embargo, la creciente centralidad europea y su indiscutible autonomía no implica la traslación de la idea de la estatalidad al ordenamiento europeo. La propuesta es fijar conceptualmente, teorizar, el nuevo espacio común que, en cualquier caso, afirma la centralidad europea en esa relación entre ordenamientos, pues la autonomía esencial, aunque predicada en cada nivel normativo, reside en el europeo que actúa de marco global.

Quizás el elemento más débil de la construcción de la «constitución compuesta» o del «constitucionalismo multinivel» sea la articulación de la legitimación de este ordenamiento global. La pretensión de dar por superadas las críticas respecto al déficit democrático europeo son poco sostenibles ${ }^{23}$. La legitimidad de este orden complejo descansa en la articulación de un «contrato social europeo» que se construye en torno a la articulación formal de un «demos» europeo y de la manifestación de voluntad del mismo a través de mecanismos indirectos y yuxtapuestos ${ }^{24}$.

La base para la articulación del «demos» europeo es la ciudadanía europea, configurada en los Tratados desde Maastricht. Esta ciudadanía débil, deudora, en su configuración formal, de la nacionalidad estatal de pertenencia, adquiere carácter central en el seno de un concepto de «ciudadanía compuesta».

De la ciudadanía débil al «demos europeo» se pasa mediante su participación colectiva

20 CASSESE, S. «L'Unione Europea come organizzazione pubblica composita» en Riv. Ital. Dir. Pubblico Comunitario. 2000, pp. 987-92.

21 PERNICE, I.«Multilevel constitucionalism and the trety of Amsterdam; European constitutionmaking revisited?» en Common Market Law Review. 1999, n³6, pp. 703 y ss.

22 WEILER, JHH. The constitution of Europe, op.cit, pp. $90 \mathrm{y}$ ss.

23 POIARES MADURO, M.«Europa: el momento constituyente» en Cuadernos de Occidente, 2002, n²49, pp. 73 y ss.

24 PERNICE, I. «De la Constitution composée de L'Europe» en Revue Trimestrielle de Droit Européenne, $2000, \mathrm{n}^{\circ} 36$, pp. 623 y ss. 
global común es afirmar que los límites de actuación se definen desde el nivel común ${ }^{33}$. Es, por tanto, el Derecho europeo el que define sus límites de acción. Lo que afecta al sistema global se define desde la perspectiva global. La auto referencia del sistema se predica esencialmente del nivel europeo, encontrando dificultad para afirmarse en los ordenamientos estatales contagiados por la inevitable conexión.

Los conflictos entre los distintos niveles del orden conjunto se resuelven desde la perspectiva de la supremacía que opera como principio general de afirmación del nivel europeo. Resulta, desde esta perspectiva teórica, difícil plantear un conflicto interordenamientos, puesto que la dualidad aparente ha acabado resuelta en la unicidad. La colisión se resuelve en el nivel común y desde esta perspectiva, además de apelando a la cooperación que implica la forma compuesta. «Dando prioridad a la norma europea contra las leyes nacionales en conflicto, sin embargo, es la consecuencia, no sólo de la necesidad de preservar el funcionamiento del sistema legal europeo, sino sobre todo, de la verdadera sustancia del concepto de derecho: la norma general de derecho requiere igual aplicación en todos los casos en los que la norma se encuentre, sin mirar a la nacionalidad de los Estados miembros en cuestión. Esta es la condición esencial de la legitimidad y aceptación del Derecho europeo» ${ }^{34}$.

Semejante planteamiento, que se deriva del monismo implícito de la fórmula resuelve el problema fundamental de la relación entre ordenamientos, diluyendo su complejidad. La respuesta a ¿quién tiene la competencia sobre la competencia? Se encuentra en el contractualismo legitimante que permite afirmar la originalidad del ordenamiento europeo, o del nivel europeo del ordenamiento compuesto.

Esta apelación contractualista que está en la base de la propuesta, lleva a confrontarse con la intergubernamentalidad de los tratados. Los Estados ya no son los amos de los tratados, sino los ciudadanos europeos. Desvinculando la fuente de legitimidad de los tratados de los Estados se refuerza la autonomía del nivel europeo. Por tanto, el problema de la competencia sobre la competencia se transforma, se resuelve en la autonomía del nivel europeo. No hay competencia sobre la competencia de los Estados miembros ni de la Unión, dirá Pernice ${ }^{35}$. «Cada responsabilidad y competencia atribuida al respectivo nivel de acción política es limitado por naturaleza, y está sujeto a las previsiones de la respectiva constitución $)^{36}$.

La Constitución compuesta acaba conformando un monismo ordinamental que sanciona, a pesar de su formulación, una estructura jerárquica inherente a todo sistema que pretende preservar su unidad ${ }^{37}$ y, como hemos dicho, la Constitución europea es considerada un sistema compuesto pero unitario.

Si la aportación de Pernice no está exenta de contradicciones, en otras formulaciones se afirma con mayor nitidez la unicidad del sistema y sus exigencias. La propuesta de Cassese comparte la descripción de la Constitución europea como compuesta, con un sistema de fuentes articulado en dos niveles: el estatal y el europeo ${ }^{38}$, pero el sistema de

25 TORCHIA, L «Una Costitutzione senza stato» en Diritto pubblico, 2001, pp.405 y ss.

26 PERNICE, I. «De la Constitution composée de L'Europe» op. cit. «Multilevel Constitutionalism in the European Union», European Law Review, 2002,nº27,pp. 511y ss.

27 TORCHIA, L. «Una costituzione senza stato» op. cit.

28 PERNICE, I. «Multilevel constitutionalism in the European Union» op. cit.

29 PERNICE, I. «De la Constitution composée de L'Europe» op. cit. 
ordenamientos nacionales por el europeo. El salto conceptual presenta lagunas evidentes y su definición no está exenta de contradicciones. La unicidad del sistema dificulta la comprensión de la construcción no jerárquica de las relaciones internas entre los dos niveles constitucionales. La pretensión de interrelación desde la autonomía de los niveles normativos no resuelve la exigencia de la unicidad que impone, necesariamente, un orden interno de sistema.

Conviven en la definición elementos de pragmatismo utilitario con otros que pretenden dar cobertura teórica a las consecuencias de la supranacionalidad de la Unión, base de la autonomía del nivel constitucional europeo.

Estas contradicciones se reflejarán en la forma en como esta propuesta articula las relaciones entre los diferentes niveles de la «Constitución compuesta». Aunque la afirmación de la ausencia de relaciones de jerarquía entre los niveles del sistema obliga a eludir el paralelismo de la Constitución compuesta con los ordenamientos federales, veremos que la afirmación de la supremacía del nivel europeo socava la autonomía de los niveles estatales. Esta contradicción obliga a una sutil diferenciación entre «federalismo supranacional» ${ }^{30}$ y Estado federal.

La forma en que se resuelve la tensión entre supremacía y relación no jerárquica resulta en exceso pragmática. Se afirma que la relación entre los dos niveles no es jerárquica, sino funcional ${ }^{31}$. «No hay a priori supremacía ni del Derecho europeo, ni de las constituciones nacionales. El mero hecho de que la constitución europea está basada sobre e incluya las constituciones nacionales, o que está basada en el deseo común de los ciudadanos de todos los Estados miembros no implica ninguna jerarquía. Ambos órdenes legales están coexistiendo, pero son parte de un sistema que debe producir al final una respuesta legal para cada caso. Este sistema es desde su origen y construcción necesariamente no jerárquico» ${ }^{32}$.

La supremacía se ve como una inevitable solución para que el sistema único funcione, es funcional. Y la supremacía no puede predicarse sino del nivel europeo, aunque sin teorizarlo como superior. Es la ley común la que debe prevalecer en un sistema común, pues es ésta la que puede asegurar la pervivencia del sistema.

Tal afirmación de la supremacía del nivel constitucional europeo se complementa o refuerza con otras normas de relación. En primer lugar, se debe destacar la obligación de lealtad de las instituciones nacionales. Es este un principio comunitario contenido en el Derecho originario de la Comunidad (artículo 10 del Tratado de Amsterdam, versión consolidada). Principio exigido por el papel asignado a las instancias estatales en la aplicación el derecho comunitario, funcional, si, a la configuración de la relación entre las dos instancias. Pero de principio funcional pasa, en su papel dentro de la Constitución multinivel, a elemento del sistema de «federalismo supranacional». El principio de lealtad implica una ordenación entre niveles, que tiene consecuencias en el orden normativo.

El ordenamiento compuesto tiene tendencialmente una vocación universalista y como tal expansiva, que dificulta la relación entre los niveles normativos. Propio de un sistema

30 PERNICE, I.«De la Constitution composée de L'Europe» op. cit.

31 PERNICE, I.«Multilevel constitutionalism in the European Law» op. cit. También NETTESHEIM, M.«El significado constitucional de la primacía del Derecho Comunitario y de la Union» en Revista Española de Derecho Europeo, 2oo3, no 6, pp. 279-89

32 PERNICE, I. «Multilevel constitutionalism in the European Lan» op. cit. 
trucción unitaria de ordenamiento global. La Constitución única, como constitución multinivel, permite sortear los problemas de la falta del político europeo, de la falta de legitimación democrática del mismo. «Los Tratados satisfacen las funciones que corresponden a una constitución: constituyen,legitiman, organizan y limitan el poder público en la relación de los órganos entre sí y tambien frente a los individuos...El caso es que, sin embargo, los Estados no son terceros para a sus ciudadanos. El Estado democrático es la organización de sus ciudadanos: solo ellos tienen la capacidad de legitimar la comunidad supranacional, de ellos recibe su autoridad» ${ }^{44}$.

Así mismo, la unión material del Derecho constitucional europeo y del de los Estados miembros ${ }^{45}$, contagia a la constitución global del papel legitimador que esta cumple en los Estados, en cuanto reguladora del poder político. Falta precisar que esta constitución unitaria se conforma, a pesar de la pretendida ausencia de relación jerarquica entre los distintos niveles, bajo la supremacía del Ordenamiento comunitario que diseña el nuevo orden global en el espacio europeo y es, precisamente este, el que viene legitimado sin vincularse a los requisitos democráticos de los Estados constitucionales.

Otras formulaciones, como aquellas que teorizan el Estado europeo como superación del Estado nacional, que deviene ahora Estado comunitario ${ }^{46}$ integrador de dos ordenamientos en una simbiosis similar, conducen a similares resultados.

\section{PROCESO CONSTITUYENTE Y PODER CONSTITUYENTE EN LA CONVENCIÓN EUROPEA.}

Hasta ahora hemos intentado una indagación en los problemas de legitimación democrática del Ordenamiento comunitario, en la medida en que la democracia, desde el fin del liberalismo monoclase, se presenta como el elemento definidor de la experiencia constituyente y necesariamente debe traducir en sus resultados sus exigencias.

Proceso constituyente y poder constituyente presentan una conexión entre democracia y libertad que se confrontan como antitesis con continuidad, sustracción al espacio político europeo al control y requisitos de democraticidad. Notese que lo que planteamos no es tanto la conexión entre poder constituyente y constitución, dando por asumida esa nueva concepción constitucional de la «constitución multinivel», funcional a la elusión política que permite la interrrelación y la articulación de los distintos niveles de poder, sino que pueda hablarse de proceso constituyente, al menos en sentido fuerte. Teorizada la constitución multinivel, la noción de proceso constituyente se disuelve en la constitución existe $^{47}$. Más aún, la propia constitución incorpora una visión de la misma como proceso ${ }^{48}$ que expresa una evolución en la interrelación de los niveles de articulación del poder según las exigencias de la construcción de orden que funda la constitución material del «Estado de mercado» y su ruptura con la forma de «Estado social».

33 PERNICE, I. «De la constitution composée de L'Europe» op. cit.

34 PERNICE, I. «Multilevel Constitutionalism in the European Union» op. cit.

35 PERNICE, I. «Multilevel Constitutionalism in the European Union» op. cit.

36 PERNICE I. «Multilevel Constitucionalism in the Europen Union» op. cit.

37 GAUTRON, J.C. «Un ordre juridique autonome et hierarquisé» en De la Communauté de Droit a L'Union de Droit. Continuités et avalars européens. L.G.D.J. Paris, 2000, pp. 25 y ss. 
relación entre los dos niveles consagra la primacía europea.

El ordenamiento comunitario, si bien compuesto, configura como elemento central del mismo el principio de unidad «todas las partes pertenecen a un sistema» ${ }^{39}$. Su carácter compuesto se explica por la evolución del proceso de integración y por la complejidad estructural del mismo, pero es impensable, como en todo ordenamiento, sin su unidad. En este caso, unidad significa ordenación interna, que se realiza bajo la prevalencia europea. El nivel común preside el ordenamiento global, ahora sin contradicciones «El derecho comunitario es un jus respecto a los jura propia de los ordenamientos particulares. Aquel alcanza a graduar la validez de las normas concurrentes, que se miden con el metro comunitario. Los derechos particulares o domésticos pueden desarrollarse en plena autonomía sólo en aquellas relaciones para las cuales el derecho comunitario no provea. En conclusión, es el jus commune el que fija el orden de las fuentes, al cual deberán atenerse los ordenamientos particulares ${ }^{40}$.

Es el principio de unidad, materializado en la unidad de mercado que, por la preeminencia de la dimensión económica en su ordenamiento el que cohesiona al sistema europeo, consolida su expresión global ${ }^{41}$. Es, desde esta perspectiva y para el conjunto del ordenamiento la unidad de mercado un «valor fundante porque está en la base de toda la construcción restante» ${ }^{42}$. Más aún explica la necesidad de unidad y sumisión al ordenamiento común e impone sus principios.

Así configurada la constitución europea compuesta, las relaciones con el nivel estatal resultan clarificadas. "Unión y Estados concurren, pero estos operan en función instrumental a la Unión» ${ }^{43}$. La Unión asume pues el papel dominante en estas relaciones.

La cuestión de la relación entre ordenamientos, desde la perspectiva de la Constitución compuesta, asume la lógica monista.

¿Como influye la teorización de la constitución compuesta en los problemas de legitimación?, en nuestra opinión de una forma doble. Por una parte debilita la transcendencia de la legitimidad directa y, por tanto, del principio democrático. Por otra refuerza la legitimación por el derecho del sistema de poder europeo.

Respecto al principio democrático, la consideración única del nuevo complejo constitucional refuerza la función legitimante de la participación democrática de los Estados miembros, minimizando el deficit democrático. El ordenamiento compuesto no precisa de una legitimación en todas sus instancias, o, al menos, una menor intensidad en una de ellas no compromete la democraticidad del sistema. Esta aparece suficientemente fundada en la instancia estatal. Sin embargo, a pesar del sofisma superador del deficit democrático, la fuga del espacio político estatal a un ámbito sin control resulta a su vez justificado por la cons-

38 CASSESE, S. «La Costituzione economica europea» en Riv. Ital. Dir. Pubblico Communitario, 2001, pp. 907 y ss.

39 CASSESE, S. «La Costituzione europea: elogio della precarietà» en Quaderni costitu₹̦ionali, 2002, $\mathrm{n}^{\circ} 3$, pp. 469 y ss.

40 CASSESE, S. «La costituzione europea: elogio della precarietà», op.cit.

41 CASSESE, S. «La costituzione economica europea» op. cit.; WEILER, J.H.H. The constitution of Europe op. cit. pp. 89-90

42 CASSESE, S. «La costituzione economica europea» op. cit.; WEILER, J.H.H. The constitution of Europe op. cit. pp. 89-90

43 CASSESE, S. «La costituzione economica europea» op. cit; WEILER, J.H.H. The constitution of Europe. op. cit. 
directa con la democracia, la configuración de la convención desdice cualquier relación con la misma, como no sea volver a teorizar un reenvio a un sistema de legitimación indirecto muy atenuado, por el papel de los Parlamentos, estatales y europeo, y los Gobiernos. A pesar de algunos juicios voluntaritas y bien intencionados ${ }^{53}$ la Convención dificilmente puede reivendicar este papel y los problemas que plantea desde esta prespectiva ha sido imposible obviarlos ${ }^{54}$. La pretendida amplitud, la atenuación de la intergubernabilidad, y la evocación terminológica no pueden suplir los problemas de democraticidad.

Si la dimensión a considerar es originalidad y libertad del poder constituyente, la autonomía de la Convención, por mucho que se pretenda decir que ha traspasado el límite de los constringentes contenidos de la declaración de Laeken, aparece comprometida, estos la sitúan más ante una perspectiva de innovación atenuada, limitada por la continuidad del modelo, que ante una actividad constituyente. Por otra parte, La relación ConvenciónConferencia intergubernamental deja pocas dudas sobre quien ostenta la titularidad constituyente, los hechos posteriores han disipado este espejismo de la convención-constituyente. La Conferencia de finales del 2003 evidenció las complejidades del funcionamiento de la constitución multinivel, pero tambien y de forma expresiva, los limites tanto innovativos como de autonomía de la apertura del método convencional.

Con independencia de la autonomía de la Convención, la cuestión fuerte se plantea no ya en la relación entre estos dos órganos (Convención y Conferencia intergubernamental) que presentaría un problema ficticio de titularidad del poder constituyente, sino de si nos encontramos ante un proceso constituyente o en una solución de continuidad, en sus aspectos determinantes, del proyecto configurado en torna a la idea de constitución compuesta. La continuidad jurídica en el proceso abierto con la Convención es evidente, los objetivos fijados en Laeken afectan a un rediseño del poder, en la dimensión más organizativa y una readaptación de los mecanismos decisionales, dificilmente puede verse en ello la esencia de la constitución ${ }^{55}$. El contenido resta vinculado al proyecto ya consolidado. Lo que compromete cualquier consideración de la Convención como proceso constituyente, no es la correspondencia con la tipicidad concentual, sino su alcance, que como hemos dicho expresa cuestiones de democraticidad de fondo y se conectan con la cuestión del poder constituyente.

La «Constitución europea» surge como una simple consecuencia funcional del proceso de integración del mercado, sin una discusión sobre los valores que esa integración económica necesariamente encarna. En otras palabras, la Constitución europea se presenta como una pura conclusión constitucional lógica derivada del proceso de integración económica que no ha sido precedida de un debate constitucional. No puede basarse en un modelo regulador y funcional cuyo fundamento de legitimidad (basado en unos objetivos predeterminados, una delegación limitada de soberanía para conseguirlos y su atribución a un poder tecnocrático) es incompatible con los procesos de constitucinalización y europeización descritos. La legitimación de proceso constitucional europeo se encuentra pues

44 PERNICE, I. «Derecho constitucional europeo y Derecho constitucional de los Estados miembros» en Revista Española de Derecho Europeo, 2003, n 8, pp 601 y ss.

45 PERNICE, I. «Derecho constitucional europeo y Derecho constitucional de los Estados miembros», op cit.

46 MANZELLA, A. «Lo Stato comunitario» en Quaderni Costituzionali, 2003, n 2, pp 273 y ss. 
La contraposición que alguna literatura hace entre tratados, incluso entre tratado constitucional, y constitución ${ }^{49}$ plantea un dilema falso. La cuestión no puede presentarse como tensión entre intergubernamentabilidad y autonomía europea, que sustraiga la decisión sobre el contenido constitucional a los Estados, el nuevo paradigma constitucional elimina esta tensión, la intergubernamentalidad es solo una forma de relación entre ámbitos de poder en la constitución compuesta, que ya ha establecido la primacía comunitaria en la definición del modelo. La forma decidida tiene que ver con la continuidad, con la elusión del debate fundamental en un texto nuevo que obliga a clarificar la ruptura con el constitucionalismo social, que todavía subsiste formalmente en los Estados miembros ${ }^{50}$.

La revisión de los Tratados, con la consiguiente continuidad formal, no contradice la existencia de una Constitución europea, sino que esta sea fruto de un verdadero proceso y poder constituyente. Expresa la caritaturización del poder constituyente, la reducción de este a poder constituido ${ }^{51}$, que funciona con una lógica contextual precedente, que niega no solo la innovación, sino la clarificación, para eludir los problemas de legitimación que plantea.

Es por eso que la idea de proceso constitucional que incorpora la constitución compuesta ( multinivel) es, no solo más explicativa, sino que resuelve un problema de aparente contradicción entre tratados y constitución o entre proceso de reforma y proceso constituyente. Proceso significa, ahora, adaptación del modelo diseñado desde la instancia europea. Supone un paso en la integración de instancias de poder en un orden único que plantea problemas de organización institucional y de disciplina de diseño en los momentos de la ampliación europea.

Aunque las consideraciones respecto al proceso constituyente europeo están presididas por esta reflexión, conviene realizar un cierto desarrollo de la contraposición entre poder constituyente y Convención europea a fin de clarificar esta contradicción.

Ciertamente la construcción conceptual del poder constituyente ha sido compleja, su juridificación es ó un intento de desnaturalización ó una tarea imposible, pero podemos situarnos en un terreno relativamente compartido, en la referencia al mismo. Desde esta perspectiva, el poder constituyente establece unas relaciones directas con la democracia, la originalidad y la libertad, desdibujar estas notas no contribuyen sino a pervertir esta noción, haciendo que la innovación que significa la ruptura de la tradición del constitucionalismo social, ocupe su lugar.

Las condiciones de democraticidad del método convencional, ya ensayado en la Carta de Derechos Fundamentales, distan mucho de ser parangonables a las exigencias que un momento fundacional y transcendente requiere. Si la misma noción de poder constituyente resiste mal su reconducción a la lógica representativa ${ }^{52}$, que evoca una conexión más

47 DOGLIANI, M. «Revisione dei Trattati o processo costituente» en Questione giustizia, 2000, $\mathrm{n}^{\circ}$ 2, pp 310 y ss.

48 PERNICE, I. «De la Constitution composée de L'Europe» op. cit

49 FRANCK, C. «Traitè et constitution: les limits de l'analogie» en La Constitucion de l'Europe. Inst. D'Etud. Europ. Bruselas, 2002. pp. 31 y ss. 310 y ss

50 DOGLIANI, M. «Revisione dei Trattati o processo costituente» en Questione giustizia, 2000, $\mathrm{n}^{\circ} 2, \mathrm{pP}$

51 PACE, A. «La dichiarazione di Laeken e il processo costituente europeo» en Riv Trim Dir. Pubblico, $2002, \mathrm{n}^{\circ} 3$, pp 613 y ss. Haciendose eco de las criticas a poder constituyente que incorpora el proceso iniciado en Laeken. 
titucional, explica su continuidad y contenido como expresión de la constitución material que impone el constitucionalismo compuesto postsocial. El proyecto de Tratado constitucional de la Convención es, ahora si, la traducción formal de la constitución material del constitucionalismo multinivel europeo, superándose la contradicción entre constitución formal de los Estados miembros y constitución material impuesta mediante el proceso de integración.

\section{LA CONTINUIDAD DEL PROYECTO DE LA CONVENCIÓN EUROPEA.}

Centraremos en dos aspectos el analisis del proyecto de la Convención que, por su significación, definen el proyecto global generalizado desde la instancia europea. El primero será el de la Constitución económica y el segundo el de los Derechos. La referencia, necesariamente somera, a la Constitución económica permitirá evidenciar como el debate en la Convención no ha logrado traducir en el texto resultante las demandas de conciliar, superando la etapa precedente, la dimensión social con las exigencias del mercado único, reproduciendo la tensión entre acumulación y legitimación que de manera radical estableció Maastricht. Los Derechos y su recepción en el texto de la Convención parecían representar el tránsito al mundo constitucional y así, se consideró como momento materialmente constituyente, la aprobación de la Carta de Niza, su inclusión en el Proyecto de Tratado debía confirmar esta interpretación. A la vez, la introducción de un catálogo de Derechos simbolizaba el paso a un constitucionalismo universalista que desmentiría la unidimensionalidad del Ordenamiento comunitario. En ambos casos podemos decir que se registra una continuidad respecto al ordenamiento anterior, que dificulta hablar de momento constituyente y menos aún de poder constituyente atribuido a la Convención. Aunque, en materia de Derechos la Convención aporta una novedad formal de relieve, la inclusión del contenido de la Carta de Niza en el Proyecto de Tratado, esto no puede leerse como corrección de la centralidad del mercado en el texto. La universalidad que visualiza la traslación de la Carta al proyecto cumple una función inversa, al introducir una lógica constitucional debil de los derechos, derivada de la vinculación con los objetivos económicos y de la centralidad de las libertades económicas, desde esta perspectiva puede decirse que la visión de los derechos que incorpora el Proyecto se contrapone a la tradición del constitucionalismo de los Estados miembros, erosionando aún más su constitución formal. Es por eso que decimos que tambien en materia de derechos se produce una continuidad, pues esa era la lógica del sistema de derechos construido hasta la aprobación de la Carta.

52 NEGRI, A. El poder constituyente. Ensayo sobre las alternativas a las modernidad. Libertarias/ Prodhufi, Madrid, 1994, pp 30-1.

53 PISTONE, S. «Costituzione europea, avanguardia federale e metodo costituente democratico» en Per una nuova governance europea, Cacucci Edt. Bari, 2002, pp 355 y ss.

54 MAcCORMICK, N. «European democracy-New directions in 2002?» en Diritto Pubblico Comparato ed Europeo, 2002-IV, pp 1526 y ss; FLORIDIA, GG. Y SCIANNELLA, G. «Siamo una Convenzione. Vale a dire che cosa?. Anatomia (e autonomia) della Convenzione europea» en Diritto Pubblico Comparato ed Europeo, 20002-III, pp 997 y ss; GATTINI, A. «Questioni di metodo nella revisione dei trattati» en Verso la Costituzione europea. Guiffré, Milan, 2003, pp 89 y ss 
cuestionada, subrayandose el deficit democrático y constitucional del proceso de integración $\diamond^{56}$ Las palabras de Poiares Maduro son reveladoras de la construcción del constitucionalismo europeo y de los problemos de transcender a este esquema, por ello dice que lo que marcaría la apertura de un proceso constituyente sería justamente romper la continuidad anteriór ${ }^{57}$, justo lo que no se ha producido.

La radical innovación y democraticidad que Negri otorga al poder constituyente ${ }^{58}$ llevan a confrontarle con el institucionalismo jurídico, en este caso con las teorizaciones sobre la constitución material ${ }^{59}$. El concepto de constitución material y su vínculo con las fuerzas hegemónicas que la predeterminan, privan de todo alcance innovador al proceso y niegan la radicalidad trasformadora del poder constituyente. La normatividad de la constitución material sustituye a la innovación de este. Por otra parte, las relaciones entre constitución formal y material en la construcción mortatiana ${ }^{60}$ convertirian al poder y al proceso constituyente en una mera transcripción de contenidos predeterminados, sería como la negación de estos conceptos. La preconstitución de la constitución material impide conceptualmente operar al poder constituyente.

Esta relectura de Negri de Mortati sugiere, al menos dos tipos de consideraciones. La primera, que a la constitución material sobrepone otras cuestiones referidas al sujeto del poder constituyente. La segunda, que la noción de constitución material puede ser útil para comprender, tanto la caracterización del nuevo constitucionalismo compuesto europeo, como el proceso de revisión de los tratados que ha puesto en marcha la Convención.

Que la solución constitucional formal este predeterminada por la normatividad de la constitucioanl material no impide hablar de poder constituyente, no supone el sometimiento, la operación disciplinante del ordenamiento a la fuerza transformadora del poder constituyente. Al contrario, significa comprender que la solución impuesta por el poder se vincula a la propuesta trasformadora que este encarna y que impulsa con su hegemonía. El problema es, pues, el del sujeto que, ciertamente en este caso, no hay por que reducirlo a la formulación mortatiana de las fuerzas políticas dominantes y menos aún a una expresión partidaria. La noción fuerte de poder constituyente, que Negri expresa, se conforma mal con el reduccionismo representativo, acentuando el momento transformador, pero no tiene porqué conducir a negar la esencia de la aportación de la idea de la constitución material.

Sin embargo la constitución material resulta especialmente útil para comprender el proceso de la construcción europea. La idea de constitución compuesta, si se entiende como forma jurídica de organización del tránsito de la forma de Estado social al Estado de mercado, en el marco de la subsistencia formal del constitucionalismo social en los Estados miembros, reclama la noción de constitución material.

Por otra parte, el proceso de reforma de los tratados, con el nuevo Tratado cons-

55 PACE, A. «La dichiarazione di Laeken e il processo costituente europeo» en Riv Trim Dir. Pubblico, 2002, $\mathrm{n}^{\mathrm{o}} 3$, pp 613 y ss.

56 POIARES MADURO, M. «Europa: el momento constituyente» en Cuadernos de Occidente, 2002, $\mathrm{n}^{\circ}$ 249 ,pp 72 y ss.

57 POIARES MADURO, M. «Europa: el momento constituyente», op cit.

58 NEGRI, A. El poder constituyente. Ensayo sobre las alternativas a las modernidad. Libertarias/ Prodhufi, Madrid, 1994, pp 17-59

59 NEGRI, A. El poder constituyente. Ensayo sobre las alternativas a las modernidad, op. cit. 
ros. Además la excepción no empaña el criterio general de sumisión a las normas de la competencia, este mandato impide el funcionamiento del servicio público, concepto distinto del de servicio de interés económico general, como mecanismo interventor de corrección del mercado ${ }^{67}$.

Finalmente realizaremos algunas consideraciones sobre el gobierno de la economía, respecto a esta cuestión abordaremos elementos generales que tienen que ver con el modelo de Constitución económica, otros referidos al presupuesto, en la medida en que predetermina la posibilidad de intervención, y los mecanismos de intervención, diferenciando tres ámbitos competenciales: política monetaria, económica y política social y de empleo.

Conviene recuperar ahora alguna consideración anterior respecto al alcance de la fórmula «economía social de mercado», como hemos dicho, esta expresión históricamente estaba lejos del significado que ha adquirido en el debate de la Convención. La escuela de Friburgo teorizaba la necesidad de una intervención económica del poder público desde la perspectiva de la garantía de funcionamiento del mercado, de tutela de la competencia como forma de preservación del espacio de intercambio, la intervención social era marginal a la lógica ordoliberal. La «economía social de mercado» establecía un modelo de intervención reguladora, más que correctora. La constitución económica europea interioriza este modelo, asume la lógica interventora del «Estado regulador» ${ }^{68}$,centrando la intervención en este extremo, la garantía de la competencia, instrumentado a través de las autoridades independientes. Esta, que era una nota caracterizadora de la Constitución económica europea, no cambia sustancialmente en el Proyecto de tratado. El Estado regulador es expresión de la centralidad indiscutida del mercado en la constitución económica.

El presupuesto comunitario, desde la perspectiva del la intervención pública, debería constituir un mecanismo instrumental, es impensable esta sin una amplitud suficiente de aquel. La crónica insuficiencia presupuestaria de la Comunidad se justifica desde la asunción de la lógica del Estado regulador. La contención presupuestaria, mantenida para el periodo 2000-6, mantiene en los mismos términos esta cuestión. Las previsiones normativas contempladas en los artículos I-53 a 56 del Tratado Constitucional inciden en la disciplina presupuestaria como criterio económico y, a pesar de una cierta apertura formal, no modifica el sistema de financiación, más aún, le definición del sistema de recursos y los límites presupuestarios se someten a un régimen de rigidez normativa e intergubernamentalidad extremos (art. I-55.2 del proyecto), lo que hace improbable su modificación.

Sin embargo el problema mayor no reside en la ausencia de un instrumento presupuestario creíble como instrumento de intervención, ni siquiera en los rígidos principios de disciplina presupuestaria, sino en las normas de disciplina presupuestaria impuestas a los Estados, que actúan como mecanismo efectivo de disciplina económica global. Los debates tendentes a la flexibilización del control del deficit público, en el seno de la Convención, dieron escaso fruto. La no exclusión de la «regla de oro» de la financiación de las inversiones en infraestructuras en el cálculo del porcentaje del deficit público, no solo endurece el control de la política económica, sino que limita el alcance de las políticas anticíclicas,

60 MORTATI, C. La Costituzione in senso materiale, Giuffré, Milan 1998. Tambien «voz Costituzione. Dottrine generale e Costituzione della Repubblica Italiana» en Enciclopedia del Diritto, Giuffré, milan, 1964, pp 947 y ss. 


\subsection{La CONSTITUCión ECONÓMiCA.}

Ciertamente el análisis sobre la Constitución económica europea excede los objetivos del presente trabajo por ello aún a riesgo de ser excesivamente reducciónista aludiremos solo a algunas cuestiones que nos parecen centrales. La primera cuestión a considerar se refiere a la definición del modelo. Sobre este debate se ha pretendido afirmar un nuevo equilibrio entre los aspectos económicos y sociales en el nuevo proyecto, más aún, consagrar el llamado «modelo social europeo», expresión, sin duda evocadora, que pretende establecer un vínculo, siquiera terminológico, con el constitucionalismo social. El punto de partida es el artículo 4 de la versión consolidada de los Tratados, la fórmula utilizada, cuya continuidad se pretendía para el texto de la Convención, era de la «economía de mercado abierta y de libre competencia». Frente a este, pronto se contrapuso otra fórmula que se pretendía expresase esa conciliación entre mercado y vínculo social, la expresión era clásica, aunque el contenido que se la quería otorgar no era el que tuvo en origen, con la fórmula «economía social de mercado» ${ }^{61}$ se intentaba, en el campo de los modelos, vincular el sistema económico con el modelo social. Ese era el significado de las propuesta del CES europeo ${ }^{62}$ y de algunos de los miembros de la convención de inspiración socialdemocrata ${ }^{63}$. Como se sabe el resultado fue distinto, un ejercicio compromisorio formal que privaba de todo significado a la expresión introducida en el proyecto. La fórmula finalmente adoptada. «economía de mercado altamente competitiva» (art-3.3 del Tratado Constitucional) pretende acentuar, frente a la interpretación que se otorgaba a «economía social de mercado» la centralidad del mercado en el modelo. La corrección, vistas las posiciones del debate, solo puede ser interpretada de esta forma. Desde el punto de vista de la referencia del modelo no puede decir que se haya registrado más que un cambio semántico. Es cierto que algunos autores no otorgaban ninguna trascendencia a las expresiones como las señaladas ${ }^{64}$, sin embargo, vistas las posiciones en confrontación, no puede ocultarse que la fórmula expresa la constitucionalización de un modelo que se contrapone al constituciona lismo económico del Estado social.

El segundo aspecto en el que queríamos detenernos es en de la relación entre normas sobre la competencia y servicios públicos. Lo hacemos porque, como se sabe, Amsterdam significó un cambio en el tratamiento de los servicios que abría las puertas a una intervención correctora frente al mercado, al menos esta era una interpretación sostenida por alguna doctrina $^{65}$. Si los efectos del Artículo 16 del Tratado han sido residuales y no han supuesto una modificación sustancial del regimen de la competencia ${ }^{66}$, la configuración de los servicios públicos en el texto del Tratado Constitucional no parece que suponga ninguna modificación transcendente. La referencia del artículo II-96, en el catálogo de derechos, dentro del apartado de la solidaridad, no parece que tenga la fuerza de desvirtuar el regimen de la competencia, primero por su formulación y segundo porque así se establece en las propias normas de interpretación y aplicación de la Carta. Si a los servicios se les otorga una función en el logro de la cohesión social, el alcance del derecho de acceso a los servicios de interés económico general no parece ser suficiente para afectar a las normas sobre la competencia.

Por otra parte, lo dispuesto en el artículo III-166 no parece incorporar cambios sustanciales. Ciertamente sanciona normativamente una excepción en la sujección a las normas sobre la competencia para las empresas que gestionen estos servicios en los supuestos en que estas normas impidan el cumplimiento de sus fines, pero no puede obviarse que la valoración de esta circunstancia se realiza por la Comisión con criterios de exigencia seve- 
Hemos señalado que la aportación fundamental del Proyecto consiste en trasformar el estatus jurídico de la Carta de Niza, incluyendo su contenido en el texto del Proyecto de Tratado, adquiriendo plena eficacia lo que antes se configuraba como «soft law». Indudablemente esto supone una novedad transcendente. Tambien hemos señalado que, sin embargo, los efectos de esta determinada constitucionalización de los Derechos, con la evidente universalización del ordenamiento europeo, son problemáticos y contribuyen a cambios en el sistema global de Derechos afectando a los sistemas nacionales. La Carta acaba produciendo una tendencial patrimonialización de los derechos que contagia a los ordenamientos nacionales en la lógica de la constitución compuesta. Antes de extendernos en esta consideración conviene hacer algunas consideraciones sobre el alcance de la Carta en el contexto constitucinal del Proyecto.

La valoración de la Carta de Niza oscila entre una visión optimista, mayoritaria ${ }^{71}$, y otra pesimista ${ }^{72}$, sin embargo determinadas cuestiones son de suficiente calado como para afectar a la influencia de la Carta en el sistema de derechos europeo, La primera cuestión que suscita perplejidad es la separación de los derechos contenidos en el Proyecto, por una parte las libertades fundamentales vinculadas a la construcción y mantenimiento del mercado único y, por otra el cuerpo de los derechos reconocidos en la Carta. Las libertadas económicas, en torno a las cuales se había articulado el sistema de derechos comunitario conservan un estatuto especial, se regulan en el artículo 4 del Proyecto. Incluir en el título I «De la definición y de los objetivos de la Unión» la tutela estos derechos supone dotarlos de una relevancia especial evidenciando la vinculación de los derechos a las exigencias de funcionamiento del mercado, que se configura como centro de definición del sistema, recuperando lo que fue la lógica de construcción jurisprudencial anterior. Mientras que los derechos de la parte segunda tienen un mecanismo de condicionamiento que afectan a su eficacia, en los del artículo 4 su autonomía y prevalencia, derivada de vinculación a los objetivos de la Unión, condicionan el contenido de aquellos. Parece que este sea el significado de la diferenciación de los dos grupos de derechos. El efecto irradiación se produce de forma inversa a al teorizada en el constitucionalismo social de la postguerra. Los derechos no condicionan al ordenamiento, especialmente en el ámbito constitucional, sino que es el mercado y la expresión juridificada de sus normas, las que afectan a estos privandoles de su autonómia desde la que vinculaban al sistema económico. Así, las normas del nuevo Tratado que desarrollan las cuatro libertades ( título III, de la tercera parte), por el sistema de reenvios establecido ( arts-4 y III-130.1 y 2) se convierten en el mecanismo de redefini-

61 DI NELLA, L. «La scuela di Friburgo o dell'ordoliberalismo» en Diritto ed economía. Problemi e orientamenti teorici, Cedan, Padua, 1999, pp. 171 y ss; Tambien MICCÚ, R. «Economía e costituzione. Una lettura della giuspubblicistica tedesca» en Quaderni del Pluralismo, 1996, $\mathrm{n}^{\circ} 1$, pp 243 y ss.

62 Ver resuloción del CES europeo de 19 de septiembre de 2002.

63 Ver contribuciones de C, EINEM Y M, BERGER (Conv. 232/02), P, BERÈS, DE 19 DE DICIEMBRE DE 2002 Y A VAN LANCKER (Conv. 86/o2).

64 TOSATO, G.L «Osservazioni in tema di Costituzione economica dell'Unione Europea». En Le riforme istituzionali e la partecipaz̧ione dell'Italia nell'Unione europea, Giuffrè, Milan, 2002, pp. 57 y ss.

65 ROSS, M. «Article $16 \mathrm{EC}$, and service of general interest: from derogation to obligation?» en European Law Review, febrero, 2000, pp. 22 y ss.

66 TOSATO, G.L «Osservazioni in tema di Costituzione economica dell'Unione Europea», op. cit. pp. 57 y ss. 
reduciendo el espacio del gobierno económico a lo residual. El antiguo artículo 104, permanence en lo sustancial.

Los instrumentos de intervención consagran lo que podriamos llamar un gobierno debil de la economía, presidido por una capacidad disciplinante fuerte en materia monetaria ( competencia exclusiva de la Unión), que asegura la conformidad al modelo global de la Constitución económica europea, por un mecanismo de orientación macroeconómica débil, que imposibilita hablar de gobierno económico, y por formas de acción en la política de empleo escasamente eficaces ${ }^{69}$ La política económica se mantiene en manos de los Estados, mientras que la Unión establece formas de sujección macroeconómicas con instrumentos débiles en relación con los Estados miembros. Este sistema, gobierno débil, manifiesta sus limitaciones de dirección global en situaciones difíciles como las actuales.

Los Estados miembros vienen obligados a realizar sus políticas económicas con sumisión al modelo general (artículo I-3 y III-177) y a las orientaciones generales establecidas por el Consejo (artículo III-178). Lo que se crea es un doble espacio de dirección económica, el estatal y el europeo, con mecanismos de contacto donde la prevalencia de la instancia europea no está definitivamente consagrada con instrumentos que aseguren la dirección global. Las GOPE (Grandes Orientaciones de Política Económica) sólo disponen de mecanismos de eficacia atenuados como la vigilancia multilateral y las recomendaciones, así como la publicidad, en los supuestos de desviación. El diseño de reparto de competencias en política económica explica dos características de la política económica comunitaria. El primero, la prevalencia de los instrumentos monetarios como forma de control de un modelo económico de fuerte prevalencia del mercado, el segundo, el carácter excesivamente generalista y débil de las GOPE. Estas, más que un instrumento de dirección macroeconómico, son una suerte de declaraciones generales y de programa débil. Desde la perspectiva del gobierno económico no se han introducido novedades en la Convención, como no sea un cierto reforzamiento de los poderes de la Comisión inferior a sus demandas basadas en criterios técnicos de eficacia, habiendo trascendido escasamente los debates registrados en torno al mismo, la debilidad del gobierno económico sigue siendo una característica de la intervención europea.

La intervención en materia de política de empleo y social, adolece de una mayor debilidad en su instrumental, reconducidas al llamado método abierto de coordinación, de escasa efectividad para la consecución de los objetivos declarados en el artículo 3. La misma asimetría en el instrumental expresa la subordinación de estos objetivos al vínculo económico. Aunque la subordinación a la lógica del mercado se expresa sin paliativos en el artículo III-203, que no es sino reproducción literal del anterior artículo 125. No hay cambios significativos que rompan la continuidad esencial en la constitución económica ${ }^{70}$.

\subsection{Los Derechos en el Proyecto de la Convención.}

67 SALVIA, F. «Il servizio pubblico: una particolare conformazione dell'impresa» en Diritto Pubblico, 2000, $\mathrm{n}^{\mathrm{o}} 2$, pp. 535 y ss.

68 LA SPINA, A. Y MAJONE, G. Lo stato regolatore, Il Mulino, Bolonia, 2000. MAESTRO BUELGA, G. «Constitución económica e integración europea» en Revista de Derecho Político, 2002, n 54, pp. 35 y ss. 
una subordinación a las exigencias de funcionamiento del sistema económico que marca una regresión respecto a su ya debilitado status constitucional.

Desde la perspectiva de los Derechos puede decirse que la Carta y su constitucionalización no han traspasado las fronteras del sistema pretoriano construido con anterioridad, con las dificultades añadidas de la formalización normativa de los problemas que planteaba este sistema.

\section{CONCLUSIONES.}

El proceso abierto por la Convención europea, que culminará, despejados ya los obstáculos que provocaron el fracaso de la cumbre de Bruxelas de finales del año pasado, con la aprobación de un Tratado constitucional de la Unión europea, no es sino la continuación, consolidándolo, del proyecto que se pone en marcha con la aceleración del proceso de integración iniciado a mediados de los años ochenta. Mantiene los problemas de legitimación que afectaban al Ordenamiento comunitario y articula un orden juridico-institucional que afecta a la continuidad formal del constitucionalismo social de los Estados miembros y a las bases del constitucionalismo de la postguerra mundial.

La continuidad señalada dificulta hablar de proceso constituyente y de ejercicio del poder constituyente europeo con referencia al contenido del Proyecto de la Convención. Poder constituyente que impone, al menos desde cierta prespectiva, una radicalidad democrática en su expresión, una libertad y capacidad trasformadora que no estan presentes en este caso. El método convencional ni siquiera puede contraponerse a la conferencia intergubernamental, que conserva su primacía decisional y en todo caso está aquejado de similares problemas de democraticidad. Los contenidos venian predeterminados, no solo por la Declaración de Laeken, a pesar de la apertura que realiza la Convención, sino por el sistema real de poderes que impuso la constitución material europea vigente. Por lo que se refiere a la capacidad trasformadora, la continuidad, en los aspectos fundamentales, es evidente. La Convención no hace sino sancionar una constitución que configuraba ya como constitución compuesta capaz de imponer un orden global que se contraponía a las constituciones formales de los Estados miembros. Operaba como instrumento de trasformación de las mismas obviando los problemas de legitimación que este proceso planteaba. El Proyecto, cuando sea finalmente aprobado, sin embargo, se pretenderá contribuya a una legitimación, aquella que presta el constitucionalismo, reforzando un orden que paradójicamente le erosiona.

La constitución multinivel o compuesta, verdadero orden global europeo ya instaurado, pretendía encubrir los problemas de legitimación democrática y ruptura de la forma Estado social mediante la sustracción de un espacio político fundamental, aquel que había construido el Estado social con la superación liberal de la separación de las esferas económica y política, a la determinación democrática, colocándolo fuera del ámbito de control para los ciudadanos, fuera de lo decidible. Paralelamente construye un sistema legitimador que pretende convalidar esa minoración del espacio político, a través del contagio de la

69 SCHARPF, F.W. «the european social model: coping with the challenges of diversity» en Journal of Common Market Studies, vol 40, pp. 645 y ss. 
ción de los derechos de la Carta, acentuando el peso que en la misma tienen los derechos económicos.

Por otra parte, una de las cuestiones que se señalaban como innovación más relevante de la Carta es la de la «indivisibilidad» de los derechos, superando la distinción y la diferenciación de status jurídico de los derechos de primera generación y el resto. Los Derechos sociales participarían de la homogeneidad constitucional de los Derechos, la difusión de su carácter de fundamentalidad permitiría superar el status constitucional débil que les había caracterizado en el constitucionalismo social ${ }^{73}$. Lo que se presentaba como un logro que transcendía al constitucionalismo social, es menos evidente de lo que formalmente parece.

Si la indivisibilidad de los derechos significa homogeneidad de status jurídico, esto no se resuelve con la mera inclusión de los Derechos sociales en la Carta, bajo el rótulo de «Derechos fundamentales», sino que hay que constatarlo en la regulación concreta. El título IV de la Carta, de la solidaridad, y algunos otros derechos encuadrables en la categoría de Derechos sociales, siguen adoleciendo de los mismos problemas de eficacia. La incorporación de formulas de mediación normativas y reenvio a legislaciones y prácticas nacionales para la determinación de sus contenidos y exigibilidad comprometen la indivisibilidad de los Dererchos. Por lo demás, la introducción de la distinción entre Derechos y principios, cuyo ámbito viene reconducido al de los Derechos sociales ${ }^{74}$, acaba por desmentir formalmente lo que ya podríamos llamar el mito de la indivisibilidad.

Finalmente, debemos aludir a una disposición que afecta radicalmente a la situación de los Derechos y evidencia la subordinación a las exigencias del mercado del sistema de Derechos, nos referimos al artículo II-112.2 que dispone que «Los derechos reconocidos por la presente Carta que se mencionan en otras partes de la Constitución se ejercerán en las condiciones y dentro de los límites determinados en éstas». Este precepto opera una suerte de desconstitucionalización de los Derechos, que pierden su primariedad sometiendose a la regulación de contenidos instrumentales y funcionales a los objetivos declarados en el artículo I-3.2. Resulta evidente que la afectación de los Derechos por la regulación de desarrollo, tanto de las libertades econímcas del artículo I-4, como de las políticas de la Unión afectan al sistema de Derechos, la prueba la tenemos en la forma en que se ha construido hasta ahora este en la Comunidad. Afirmar la prevalencia de estas regulaciones frente a la primariedad de los Derechos conduce a socavar la posición constitucional de estos.

Si puede hablarse de una afectación general del sistema, no puede ocultarse que esta disposición incide de forma más aguda en el ámbito de los derechos sociales, produciendo

70 DI PLINIO, G. «La costituzione economica nel processo costituente europeo» en Diritto Pubblico Comparato ed Europeo, 2003-IV, pp. 1781 y ss. Tambien, en la misma revista, DORDI, C. Y MALATESTA, A. «La politica economica e monetaria nel progetto di costituzione europea», pp. 1796 y ss.

71 BARBERA, A. «La Carta europea dei diritti e la costituzione italiana» en La libertà e i diritti nella prospettiva europea, Cedam, Padua, 2002, pp 112 y ss; RODOTA, S. «La Carta come atto politico e come documento guiridico» en Riescrivere $i$ diritti in Europa. La Carta dei diritti fondamentali dell'Unione europea, Il Mulino, Bolonia, 2001,pp 54 y ss; BRONZINI, G. «L'Europa dei diritti dopo la Convenzione» en Questione giustizia, 2003, nº 4, pp. 727 y ss.

72 FERRARA, G. «Da Weimar a Maastricht» en La Rivista del manifesto, ottobre, 2000, pp. 24 y ss; DI PLINIO, G. «La Carta de diritti nel processo di integrazione europea» en I diritti fondamentali dopo la Carta di Niza. Il costituzionalismo dei diritti, Guiffrè, Milan, 2001, pp. 145 y ss. 
73 GIUBBONI, S. «Diritti e politiche nella «crisi» europea» en Quaderni Rassegna Sindacale, 2004, n 1, pp. 115 y ss.

74 RUBIO LLORENTE, F. «Mostrar los derechos sin destruir la Unión (consideraciones sobre la Carta de Derechos Fundamentales de la Unión Europea) en La encrucijada constitucional de ña Unión europea, Madrid, Civitas, 2002, pp. 113 y ss. 
democraticidad estatal al proyecto global. Resulta de esta manera sancionada, con una apariencia de legitimidad, la trasformación de la constitución material que se había operado en los Estados durante la década de los noventa. Debe tomarse consciencia de la nueva relidad interordinamental creada para comprender el significado y alcance del proyecto europeo y la propuesta de la Convención, que supera el debate sobre la relación entre ordenamientos estatales y el europeo tal y como se venía planteando, es decir en clave de relación conflictiva. Así se podrá comprender mejor la aportación de la Convención a la consolidación del proyecto, puesto en marcha hace ya tiempo. La lucha por la creación de un espacio político europeo, que cree las condiciones democráticas para la determinación europea, será el comienzo del verdadero proceso constituyente, negado por la revisión de los Tratados que ahora se nos presenta como la novedad constitucional que permitirá la articulación de la Europa del siglo XXI. 
